\title{
O livro didático na educação infantil : reflexão versus repetição na resolução de problemas matemáticos
}

Ana Carolina Brandão

Ana Coelho V. Selva

Universidade Federal de Pernambuco

\section{Resumo}

0 artigo analisa livros didáticos de matemática utilizados em salas de educação infantil, especificamente o tópico de resolução de problemas de estrutura aditiva. Foram examinadas doze coleções de livros, a partir de quatro eixos: a forma de introdução aos conceitos de adição e subtração; os tipos de problemas propostos; a utilização das ilustrações nos enunciados dos problemas; e o tipo de registro solicitado às crianças.

Constatou-se que os livros didáticos analisados apresentam uma pequena variedade em relação à estrutura dos problemas. Assim, problemas envolvendo adição se limitam às estruturas de combinação e transformação e a maioria dos problemas de subtração restringe-se à estrutura de transformação. Em relação às ilustrações, observou-se que este recurso é bastante utilizado para fornecer os dados no enunciado do problema. Notaram-se, ainda, vários casos em que a própria ilustração fornece a resposta. Quanto ao tipo de registro, evidenciou-se que este se limita, geralmente, à solicitação da escrita dos dados e da resposta do problema em espaços previamente determinados. Freqüentemente é indicado o sinal da operação esperada para a solução do problema.

Conclui-se que os livros didáticos de pré-escola analisados pretendem trabalhar com resolução de problemas, no entanto, as situações propostas são repetitivas e não estimulam o desenvolvimento e o confronto de estratégias diversas por parte das crianças.

\section{Palavras-chave}

Correspondência para:

Educação infantil - Livro didático - Problemas matemáticos Av. Bernardo Vieira de Melo, 5392 - apto. 61 - Candeias Ensino de matemática.

54450-020 - Jaboatão dos Gua-

rarapes - PE

e-mail:

anaselva@elogica.com.br 


\section{The textbook in child education : reflection versus repetition in the solution of mathematical problems}

Ana Carolina Brandão

Ana Coelho V. Selva

Universidade Federal de Pernambuco

Correspondence:

Ana Carolina Brandão

Av. Bernardo Vieira de Melo,

5392 - apto. 61 - Candeias

54450-020 - Jaboatão dos Gua-

rarapes - PE

e-mail:

anaselva@elogica.com.br

\section{Abstract}

The article discusses the issue of mathematics textbooks used in child education analyzing specifically textbooks that deal with problem solving. Twelve series of textbooks were examined, and the analysis was developed around four pivotal aspects: the form of introduction to the concepts of addition and subtraction, the types of problems proposed, the use of illustrations in the description of the problem, and the type of record asked from children.

It has been found that the textbooks examined display little variety with respect to the structure of problems. Thus, problems involving addition are limited to structures of combination and transformation, and the majority of subtraction problems are restricted to the structure of transformation. It has been observed that illustrations are often employed to supply the data related to the problem. In many cases, it has been noted that the illustration itself furnishes the answer to the problem. As to the types of record requested from children, it was clear that they are usually limited to writing the data supplied and the answer in predetermined spaces. Frequently the sign of the operation "expected" to solve the problem is indicated.

The study concludes that the pre-school textbooks analyzed intend to work with the issue of problem solving but the situations proposed are repetitive and do not stimulate children to develop and contrast different strategies of solution.

\section{Key words}

Child education - Textbooks - Mathematical problems. 
Recentemente, os livros didáticos de matemática de $1^{\text {a }}$ a $4^{\text {a }}$ série têm sido alvo de análises detalhadas por especialistas na área', fornecendo-se, ao professor desse nível de ensino, critérios para uma escolha mais consciente do livro a ser utilizado com seus alunos.

Em relação à educação infantil encontra-se uma série de trabalhos que discutem a qualidade das cartilhas (Barbosa, 1992; Kaufman; Rodrigues, 1995; Brandão; Guimarães, 1997). No entanto, o que dizer dos livros didáticos de matemática que são utilizados nas salas de educação infantil²? Qual a qualidade destes livros?

0 presente trabalho pretende contribuir nessa direção, enfocando os livros didáticos de matemática, analisando especificamente como tais livros vêm tratando o tópico relativo à resolução de problemas, no campo das estruturas aditivas.

Antes de apresentar a metodologia empregada nesse estudo, vale esclarecer que embora tenhamos optado por tratar o tema relativo à resolução de problemas com crianças pequenas, não estamos defendendo uma concepção de educação infantil em que o desenvolvimento cognitivo seja o mais importante ou até o único objetivo a ser considerado. Muito ao contrário, preocupa-nos a idéia de acelerar o desenvolvimento infantil e a conseqüente preocupação em manter as crianças "sentadinhas e quietinhas", realizando atividades quase sempre pouco atraentes e desafiadoras. De fato, diversos trabalhos (Silva, 1987; Gonçalves, 1994; Nunes, 1995; Wajskop, 1995) têm evidenciado o descaso de parte das pré-escolas brasileiras em relação ao espaço para a brincadeira e desenvolvimento da autonomia, da auto-estima, da criatividade, do espírito cooperativo, expressão verbal e não verbal, entre outros aspectos tão fundamentais para a formação da criança.

Neste contexto, entendemos que discutir a resolução de problemas na educação infantil é apenas mais um aspecto a que deve estar atento o educador no momento em que define os objetivos para o grupo de crianças com o qual trabalha.

Um outro ponto que também merece ser esclarecido diz respeito à própria definição do que se considerou problema, já que este será o foco da nossa análise. Adotamos a definição de Vergnaud (1982), que entende um conceito matemático a partir da existência de três aspectos: invariantes, situações e representações. Os invariantes correspondem às propriedades do conceito, as situações thes conferem significado e os simbolos são as representações do conceito. Em outras palavras, foi considerada problema a atividade proposta nos livros didáticos que requeresse o uso de um sistema matemático de representação, que, por sua vez, estivesse relacionado com uma situação em que pudesse ser utilizado, tendo como invariante a compreensão da lógica da adição e subtração.

Alguns estudos (Hughes, 1986, por exemplo) têm mostrado que crianças em torno de 4 anos já têm habilidade para resolver problemas desde que dadas as condições adequadas. Sabe-se ainda que, mesmo antes de entrarem na escola, as crianças já resolvem problemas criando, até mesmo, suas próprias estratégias de solução, como já demonstraram Groen e Resnick (1977) e Ginsburg (1977). Em situações informais, também é possível observar crianças resolvendo problemas envolvendo divisão, soma ou subtração de objetos. Assim, cabe discutir a possibilidade de explorar esse interesse espontâneo sobre quantidades, que as crianças parecem demonstrar, estimulando a partir da pré-escola o desenvolvimento de uma compreensão mais ampla da realidade utilizando os recursos que a matemática pode oferecer.

1. Ver por exemplo: Guia de Livros Didáticos $-1^{\mathrm{a}}$ a $4^{\mathrm{a}}$ séries, MEC - Ministério de Educação e do Desporto, 1998.

2. Em um levantamento recente realizado na cidade do Recife foi verificado que entre 28 escolas particulares consultadas, apenas três não adotavam livros didáticos de matemática para crianças menores de 6 anos. 
Temos, ao contrário, observado um ensino com ênfase em procedimentos que tornam a matemática algo arbitrário e destituído de sentido (Carraher; Carraher; Schliemann, 1988). Através de suas investigações, Vergnaud (1982) evidenciou que a maioria das dificuldades apresentadas pelas crianças são referentes ao cálculo relacional (relativo à compreensão das relações numéricas envolvidas) e não ao cálculo numérico (relativo ao uso do algoritmo).

Defendemos, assim, um espaço para a resolução de problemas nas salas de educação infantil, lembrando que isto não significa o treino de algoritmos, mas sim, mais uma possibilidade para o desenvolvimento do pensamento lógico-matemático das crianças.

No próximo tópico, discutiremos o campo das estruturas aditivas, apresentando os tipos de problema nele inseridos, contribuindo, dessa forma, para uma melhor compreensão da análise que foi conduzida em relação aos problemas matemáticos encontrados nos livros didáticos para as classes de educação infantil.

\section{O campo das estruturas aditivas}

Diversos autores têm analisado os tipos de problemas de adição e subtração (Carpenter; Moser, 1982; Rilley, Greeno; Heller, 1982; Fenemma; Carpenter, 1991). Segundo eles, existem quatro classes de problemas:

1. Problemas que envolvem mudança, transformação - implicam uma ação direta que causa um aumento ou decréscimo dessa quantidade. Exemplos: João tinha 8 carrinhos. Ganhou mais 6 de sua mãe. Quantos carrinhos João tem agora? Ou: João tinha 8 carrinhos. Quebraram-se 6 carrinhos. Quantos carrinhos João tem agora?

2. Problemas que envolvem combinação - implicam relações estáticas entre uma quantidade e suas partes. Exemplos: Numa partida de voleibol estão jogando 8 meninos e 6 meninas. Quantas crianças estão jogando vôlei? Ou: Numa partida de voleibol estão jogando 14 crianças. 8 são me- ninos. Quantas meninas estão jogando? 3. Problemas que envolvem comparação - implicam a comparação entre duas quantidades. Exemplos: Pedro tem 8 carrinhos e João tem 6 carrinhos. Quantos carrinhos Pedro tem a mais do que João? Ou: João tem 6 carrinhos, ele tem 2 a menos do que Pedro. Quantos carrinhos Pedro tem?

4. Problemas que envolvem igualização implicam a mudança de uma das quantidades para que uma comparação (uma igualdade) seja estabelecida. Exemplos: Maria tem 8 botões vermelhos e 6 azuis. Quantos botões azuis ela precisa comprar para que fique com a mesma quantidade de botões vermelhos? Ou: Maria tem 8 botões vermelhos. Se ela perder 2 ficará com a mesma quantidade de botões azuis e vermelhos. Quantos botões azuis ela tem?

Vale ressaltar que, em todas as classes de problemas, poderá haver variações em função do lugar que a incógnita ocupa. Tais variações são importantes, pois, para a criança pequena, cada uma destas mudanças gera um problema diferente, podendo envolver, por sua vez, estratégias distintas de solução.

\section{Objetivo do estudo}

Diante das considerações feitas na introdução deste trabalho, partimos para a análise de algumas coleções de livros didáticos de matemática adotadas em pré-escolas do Recife, discutindo como tais livros vêm propondo o trabalho relativo à resolução de problemas, no campo das estruturas aditivas. Pretendíamos, portanto, responder a três questões básicas que se desdobraram em outras, como poderá ser verificado na análise que se seguirá. São elas: os livros propõem ou não um trabalho com resolução de problemas?; que tipo de trabalho é proposto?; o que pode ser dito em relação à qualidade deste trabalho? 


\section{Método}

Foram analisadas 12 coleções de livros didáticos de matemática, dirigidos à faixa préescolar. Tais coleções foram escolhidas após um levantamento em 28 escolas particulares do Recife, localizadas em bairros de classe média e alta da cidade. As coleções analisadas variavam em relação ao número de volumes que as compunham: havia apenas uma coleção com quatro volumes, sendo as demais formadas por três volumes (seis) ou se constituíam em livros exclusivamente dirigidos às crianças da alfabetização (cinco). Os títulos selecionados encontram-se no anexo 1.

A partir de uma rápida análise de alguns livros de matemática dirigidos à educação infantil, e da leitura dos critérios adotados pelo MEC para análise do livro didático de matemática de $1^{\text {a }}$ a $4^{\text {a }}$ série, foi elaborada uma ficha de avaliação, que seguia basicamente quatro eixos: formas de introduzir o conceito de adição e subtração; tipo de problemas apresentados; formas de utilização das ilustrações que comumente acompanham os enunciados dos problemas; formas de registro da solução dos problemas propostos.

As fichas de avaliação dos livros foram revistas por um segundo juiz, e a partir delas foram elaboradas algumas tabelas para facilitar a leitura dos dados. A análise de natureza quantitativa (estatística descritiva) e qualitativa será apresentada a seguir.

\section{Resultados}

\section{Quanto à introdução aos conceitos de adição e subtração}

Neste item procuramos analisar como os livros didáticos introduziam os conceitos de adição e subtração. Ou seja, se através de contas, problemas ou definições.

Inicialmente, é interessante notar que a proposta de resolução de problemas de adição e subtração foi, comumente, encontrada apenas nos livros destinados às turmas de alfabetização. Somente uma coleção também apresentou problemas distribuídos entre os volumes destinados às séries anteriores. Quanto à abordagem dada aos conceitos de adição e subtração, verificamos que, em grande parte das coleções, estes conceitos são introduzidos através da apresentação de um problema resolvido. Ou seja, há um problema, seguido de sua solução através de uma conta, conforme pode ser visto no exemplo abaixo retirado do livro Construindo na pré-escola (vol. 3, p.96). Exemplo: João tem 1 carrinho vermelho e mais 2 carrinhos azuis. Vamos ver quantos carrinhos ele tem? Observe:

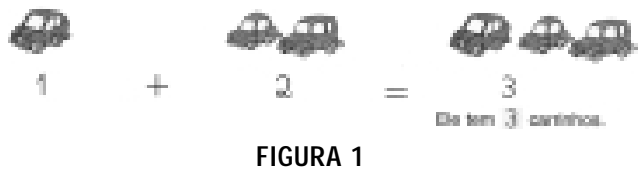

Observamos ainda uma coleção que apresentou uma definição e um problema resolvido, tanto para adição como para subtração, seguida de atividades para serem solucionadas. Em algumas coleções não foi observada uma introdução formal aos conceitos de adição e subtração, ou seja, o trabalho com as operações iniciava-se a partir de atividades (problemas e/ou contas) para o aluno resolver, sem qualquer explicação ou situação resolvida anteriormente. Isto ocorreu mais freqüentemente em relação à operação de subtração. Estes dados podem ser melhor observados no Gráfico 1.

Vale observar que a maior freqüência para iniciar o trabalho com as operações foi a

GRÁFICO 1:

Freqüência de coleções $X$ Forma de introdução aos problemas

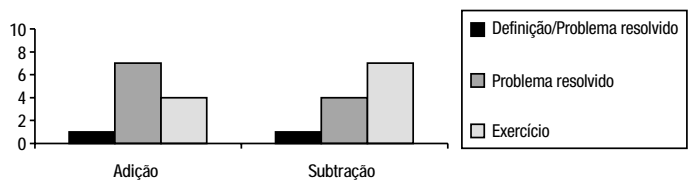


partir de problemas resolvidos e exercícios para serem solucionados pelas crianças, o que representa algo bem diferente do que ocorria há algum tempo atrás, quando os livros enfatizavam as definições dos conceitos, para depois enfocarem suas aplicações, que se restringiam quase exclusivamente ao treino do algoritmo. No entanto, mesmo propondo-se problemas para enfocar as operações, ou seja, buscando-se dar um maior sentido à aprendizagem da criança, não foi observada variação na estrutura dos problemas que serviam como exemplos. Assim, não encontramos nos livros o uso de mais de um tipo de problema resolvido para exemplificar as operações, sendo tais problemas sempre do tipo combinação ou transformação para adição e transformação para subtração. Também devemos notar que nos problemas-exemplos nunca havia qualquer variação do lugar da incógnita. Desta forma, nos problemas de combinação as partes eram dadas buscando-se a junção entre elas e nos problemas de transformação eram dadas a quantidade inicial e a transformação, devendo ser encontrado o resultado final. Parece, portanto, que, ainda que se considere a importância da criança compreender as operações a partir de situações que lhes dêem significado, apresenta-se apenas um único tipo de situação, não oportunizando uma compreensão mais ampla do conceito que se deseja ensinar.

\section{Quanto à estrutura dos problemas apresentados}

Em geral, as coleções investigadas apresentavam problemas de combinação e/ou transformação para serem resolvidos com uso da adição e problemas de transformação para o uso da subtração, sendo o resultado final quase sempre a incógnita a ser obtida. No Gráfico 2 podemos observar a freqüência de coleções em função das estruturas de problemas propostas nas operações de adição e subtração.

Em relação à adição, com exceção de uma coleção que não apresentou problema, observamos que todas as demais (11 coleções)
GRÁFICO 2:

Freqüência de coleções X Estrutura dos problemas

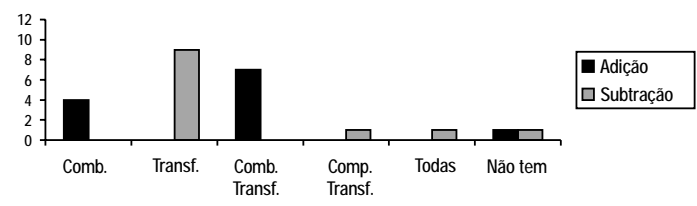

apresentaram problemas de combinação para serem resolvidos pelas crianças. Sete dessas coleções propuseram também problemas de transformação. Problemas de comparação não foram verificados em nenhuma coleção. Comparando-se o número total de problemas de combinação e de transformação encontrados em todas as coleções, verificamos que 90\% dos problemas são de combinação e apenas 10\% de transformação, o que demonstra a pequena variação das estruturas das situações-problema.

Analisando os dados relativos à operação de subtração, observamos uma predominância no uso de problemas de transformação (9 coleções). Lembramos que, no tópico anterior, quando analisamos os tipos de problemas usados na introdução ao trabalho com a subtração, constatamos que este foi o único utilizado. A análise do total dos problemas apresentados nos livros didáticos indica que 94.4\% dos problemas de subtração apresentados são de transformação, 5,2\% de comparação e $0,4 \%$ de combinação. Ou seja, as crianças são, predominantemente, estimuladas a usar a operação de subtração para resolver apenas problemas de transformação, o que certamente implicará uma compreensão bastante restrita deste conceito.

Finalmente, os problemas apresentados nos livros didáticos em geral tratavam de situações resolvidas por um único cálculo. Em dois livros, entretanto, Fazendo e compreendendo matemática e Bom tempo, encontramos problemas que envolviam várias etapas de resolução, gerando um maior desafio para as crianças, na medida em que exigiam mais 
operações de pensamento por parte delas. Vejamos um exemplo do livro Fazendo e compreendendo matemática (p.156-157).

Na página 156 aparece o desenho de um parque de diversões e de uma bilheteria com uma tabela de preços dos brinquedos. 0 valor dos brinquedos é dado pela quantidade e cor das fichas, assim, a roda gigante vale duas fichas vermelhas, o trem-fantasma duas fichas azuis, uma verde e uma vermelha, e assim por diante. A página seguinte apresenta as seguintes questões:

1. Desenhe as fichas que cada criança gastou.

A. Edu brincou duas vezes na Roda Gigante. Ele gastou: ...

B. Lena andou no trem-fantasma e no carrinho bate-bate. Ela gastou: ...

C. Marina passeou 3 vezes no trem-fantasma. Ela gastou: ...
D. Pedro atirou 2 vezes no tiro-ao-alvo. Ela gastou:

2. Desenhe as fichas que as crianças gastaram, ao todo.

Problemas como esse que estimulam a criança a refletir, estabelecer relações e operar, não são comuns nos livros de pré-escola. Como pudemos constatar neste estudo, parece haver uma preocupação em simplificar, poupar a criança de raciocínios mais elaborados. ${ }^{3}$ No entanto, mais adiante, essa mesma criança passará a ser cobrada para resolver problemas dessa natureza.

Outro problema bastante interessante também encontrado no livro Fazendo e compreendendo matemática (p. 135) foi o seguinte:
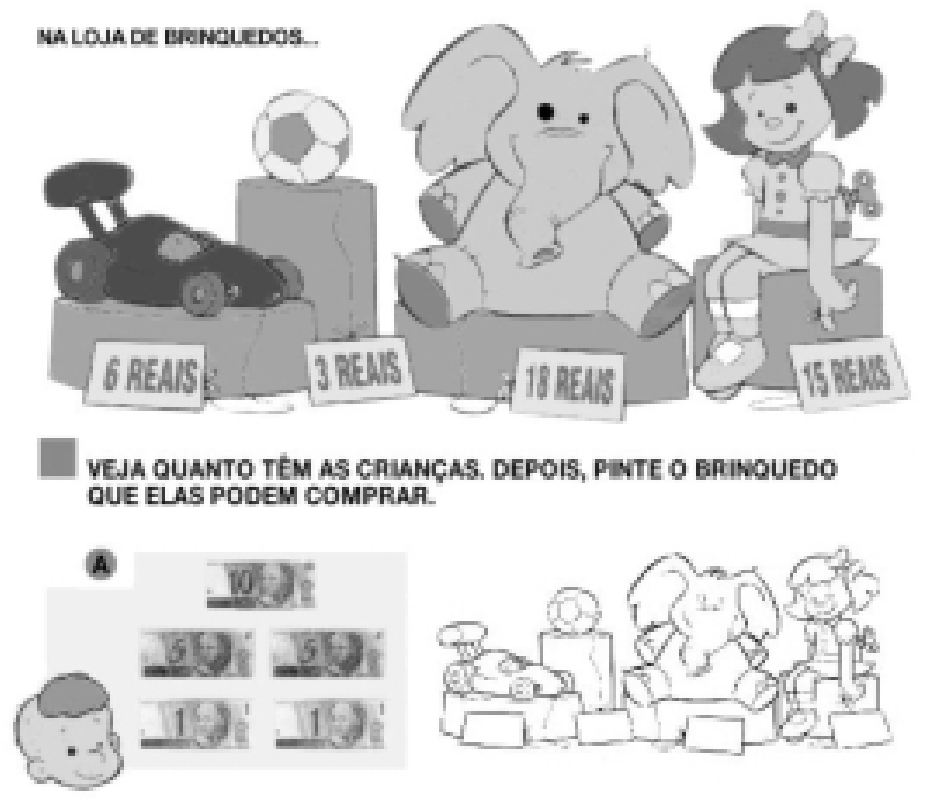

VAI SOBRAR DINHEIRO? QUANTO?

FIGURA 2

3. Vale ressaltar que há problemas que embora exijam um único cálculo, apresentam enunciados difíceis de serem compreendidos até mesmo por adultos. Por outro lado, é possível propor situações-problema mais complexas, perfeitamente passíveis de compreensão por parte de crianças pequenas. 
Nesse problema, constatamos o uso de uma situação de compra de brinquedos que trabalha conjuntamente a compreensão do nosso sistema monetário, a adição (somar as cédulas, somar o preço dos brinquedos que serão comprados), a subtração (subtrair o preço dos brinquedos da quantia de dinheiro que a criança possui) e que permite à criança fazer opções sobre o que comprar gerando diferentes respostas, que podem ser aproveitadas pelo professor para enriquecer o conhecimento matemático das crianças. Tais atividades, que se articulam com o cotidiano, parecem contribuir para uma aprendizagem mais significativa da matemática.

Um fato que devemos ressaltar refere-se à variação da quantidade de problemas encontrados nos livros. Comparando-se problemas de adição e de subtração, é interessante notar que, em cinco coleções, a quantidade de problemas de adição foi bastante superior à quantidade de problemas de subtração (menor diferença de nove e maior de sessenta e sete problemas). Em duas coleções aconteceu o inverso: a quantidade de problemas de subtração superou a de adição (uma coleção supera em nove e a outra em dezesseis). E encontrou-se, em cinco coleções, um número aproximado de problemas de adição e subtração (variação de no máximo três problemas). Esses dados parecem indicar uma preferência por situações-problema para serem resolvidas através da adição, possivelmente por se considerar esta operação mais fácil do que a subtração.

Analisando separadamente o tópico da adição, observam-se coleções em que um único volume apresenta 101 problemas, enquanto uma outra coleção apresenta apenas um problema. 0 mesmo acontece no caso da subtração, em que encontramos 118 problemas em um livro, encontrando-se em outra coleção um único problema. Esses dados parecem indicar grandes diferenças na compreensão do processo de ensino-aprendizagem das operações. Assim, ou peca-se pelo excesso, acreditando-se que quanto mais atividades melhor, ou pela quase exclusão, como se crianças pré-escolares não pudessem ser estimuladas a resolver problemas aritméticos. Também devemos lembrar que o número excessivo de problemas significa repetição de atividades semelhantes, pois como já mencionamos, quase não há variação na estrutura dos problemas propostos.

Em relação aos pares numéricos envolvidos nos problemas de adição e subtração, observamos que 92\% dos problemas de adição e 95\% dos problemas de subtração envolvem pares numéricos menores que 10. Esse uso bastante reduzido de pares numéricos maiores que 10, mesmo nos livros didáticos para as séries de alfabetização, necessita ainda ser melhor investigado. Num estudo anterior (Selva; Brandão, 1999) mostramos que o uso de números inferiores a dez parece conduzir à utilização quase exclusiva de estratégias de modelagem ${ }^{4}$ para a resolução de problemas, não estimulando a elaboração de novas estratégias por parte da criança.

\section{Quanto às ilustrações dos problemas}

0 Gráfico 3, abaixo, evidencia que os enunciados dos problemas apresentados nos livros estão quase sempre acompanhados de ilustrações, que assumem diferentes funções. Assim, as ilustrações ora aparecem apenas como acessórios para enfeitar os problemas,

GRÁFICO 3:

Percentual de uso de ilustração X Operação

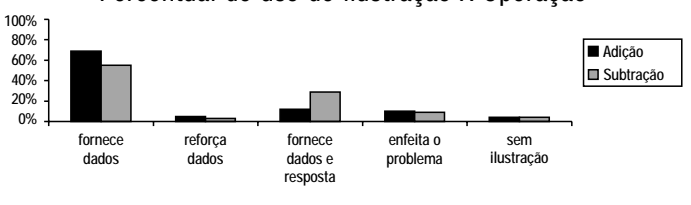

4. Terminologia utilizada por Fennema; Carpenter (1991). Referem-se às estratégias em que a criança representa diretamente as quantidades e ações descritas no enunciado do problema. Assim, por exemplo, no problema "Marcela comprou 8 chocolates e comeu 2. Quantos chocolates Marcela ainda tem?", a criança representa 8 chocolates por meio de algum objeto ou dos próprios dedos e, então, excluiria 2 objetos (ou dedos). A contagem dos objetos (ou dedos) restantes indicaria a quantidade final de chocolates de Marcela. 
ora são elementos essenciais para a resolução dos mesmos, na medida em que fornecem os dados da operação que a criança deverá realizar.

De fato, considerando um total de 414 problemas de adição e 286 problemas de subtração, constantes nas 12 coleções consultadas, apenas $4 \%$ de ambos os tipos de problemas não apresentaram ilustrações em seus enunciados. Por outro lado, foi bastante freqüente a utilização de ilustrações para fornecer os dados do problema (69\%, no caso de problemas de adição e 55\% nos problemas de subtração). Por exemplo, no livro Construindo $a$ pré-escola (v.3, p.121) encontramos o seguinte problema:

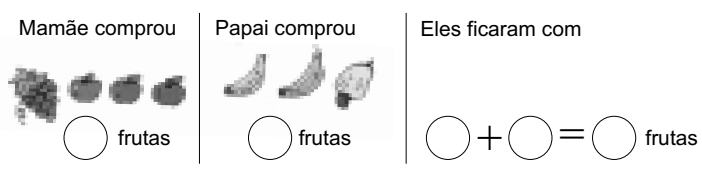

FIGURA 3

É possível que essa apresentação dos dados através de desenhos tenha a intenção de fazer com que a criança realize a contagem de elementos, criando também mais uma oportunidade para o trabalho com a escrita de numerais. Também é possível que tal opção pretenda facilitar a compreensão do enunciado, já que trata-se de crianças que ainda não lêem convencionalmente.

Notou-se ainda a presença de alguns problemas (5\% para adição e 3\% para subtração) em que embora os dados numéricos sejam fornecidos no enunciado, este é reforçado por ilustrações que indicam as quantidades já dadas no problema. Ao que parece, tal procedimento busca, mais uma vez, facilitar a compreensão da criança sobre o que é solicitado no problema.

Também no Gráfico 3 encontram-se problemas em que as ilustrações, além de fornecerem os dados do problema, davam a própria resposta (12\% para adição e $29 \%$ para subtração). Isto pode ser visto no exemplo abaixo (Lápis na mão, v. 4, p.119).

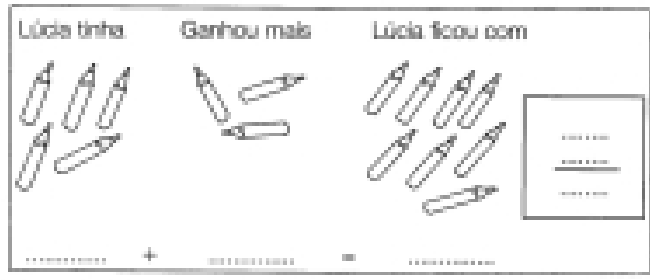

FIGURA 4

Em alguns casos, a presença das ilustrações substituiu o enunciado do problema. Vejamos um exemplo em que isto ocorreu associado ao fato da ilustração fornecer a resposta esperada (Construindo na pré-escola, v.3, p.140).

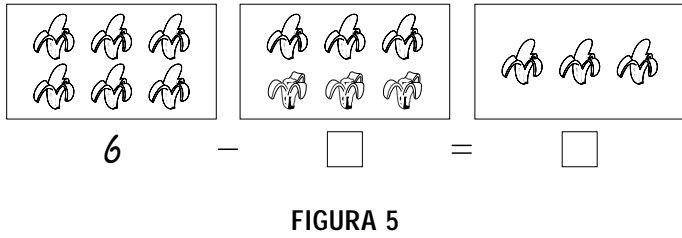

$\mathrm{Na}$ verdade, é importante observar que neste tipo de utilização da ilustração não se exige, propriamente, que a criança resolva um problema. Pede-se apenas que ela conte os elementos dos desenhos e escreva os numerais correspondentes nos espaços determinados. Dessa forma, para dar sua resposta, não é preciso sequer compreender a situação-problema colocada. Ainda em relação à figura 5, outro aspecto que podemos notar refere-se às diferentes interpretações que as ilustrações podem suscitar. Assim, além de entender o problema como referindo-se à subtração de três bananas comidas de um total de seis bananas inteiras (a compreensão esperada), a criança poderia compreender de forma diferente. Seria possível, por exemplo, entender as ilustrações como indicando a subtração de bananas sem identificar que havia bananas inteiras e bananas comidas. Tal compreensão,porém, resultaria na operação “6 - $6=3$ ”, matematicamente, incorreta. Outra interpretação possível seria, no quadro relativo ao subtraendo, somar as metades das três bananas já comidas, que 
totalizaria uma banana e meia, e adicionar às três bananas inteiras, encontrando 4,5 bananas. Esta interpretação geraria a operação “6 - 4,5 = 3", também, matematicamente incorreta. Diante disso, ao utilizar ilustrações sem enunciado é preciso estar atento para evitar ambigüidades que podem confundir a criança, ao invés de contribuir para a sua compreensão.

Ainda em relação a essa categoria, vale observar que o percentual de problemas de subtração que utilizaram as ilustrações dessa maneira foi maior do que o de adição. Este fato parece reforçar a idéia de que, para os autores dos livros, os problemas de subtração são mais difíceis para as crianças do que os de adição, sendo a ilustração utilizada como recurso para ensinar a resposta correta.

Finalmente, há alguns casos em que a ilustração funciona apenas para enfeitar o problema (10\% para adição e 9\% para subtração). Por exemplo, num problema em que o enunciado solicita que alguns lápis sejam adicionados, há no início da página, o desenho de um lápis somente para ilustrar.

\section{Quanto à forma de registro da solução do problema}

0 último aspecto analisado nas coleções foi o tipo de registro que o problema solicitava. Ou seja, de que forma a resolução da criança deveria ser registrada no livro. 0 Gráfico 4 apresenta os percentuais relativos aos tipos de registro solicitados em função dos problemas de adição e subtração.

Nota-se que em mais da metade dos problemas, seja de adição (55\%) ou subtração

GRÁFICO 4:

Percentual de tipos de registro $X$ 0peração

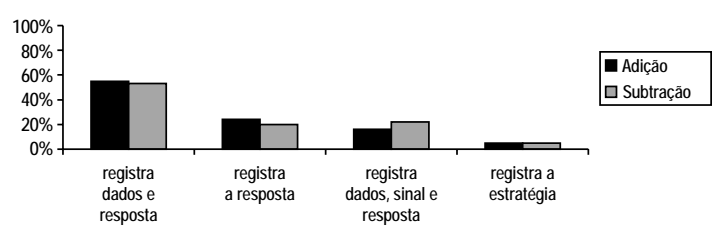

(53\%), a criança devia escrever os números referentes aos valores dados no enunciado do problema e a sua resposta. Nesses casos, vale observar que o espaço para a escrita dos números era delimitado por quadradinhos ou pontinhos, sendo também já definido o sinal da operação esperada. Com isso, obtinha-se o seguinte padrão de registro $\ldots . . .+\ldots . .=\ldots .$. ou $\ldots . . . . . . .=\ldots .$. , conforme pôde ser visto nos exemplos apresentados anteriormente, quando da discussão acerca das ilustrações.

Nota-se, ainda, que $24 \%$ dos problemas de adição e $20 \%$ dos de subtração solicitavam apenas o registro da resposta. É importante frisar que, considerando o total de problemas nesta categoria específica, $51 \%$ dos problemas de adição e $84.4 \%$ de subtração também já forneciam o sinal da operação esperada. Ou seja, a criança escreve a sua resposta observando, por exemplo, o seguinte modelo: $7-4=\ldots . .$. . Assim, a única diferença em relação à categoria discutida no parágrafo anterior é que no lugar dos quadradinhos para preencher com os números dados no problema, os algarismos já estão registrados no livro. Vejamos um exemplo (Roda gigante, v.3, p.100):

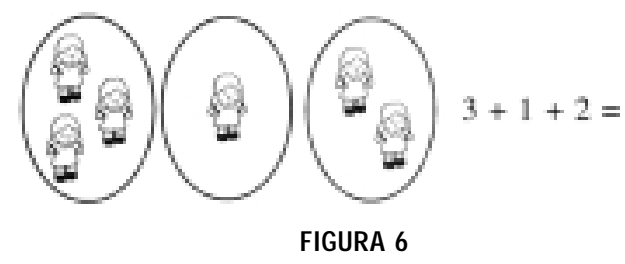

Vamos juntar brinquedos?

Vale ainda refletir sobre o percentual expressivo de problemas em que os sinais da operação já estão definidos no livro, sendo este fato mais freqüente nos problemas de subtração. Cabe questionar esta necessidade de indicar para a criança a operação que se deseja que ela utilize em sua solução. É possível que esse procedimento revele uma preocupação em facilitar para a criança o processo de resolução dos problemas. Também é possível, especial- 
mente no caso dos problemas de subtração, que a intenção dos autores seja a de garantir o uso do algoritmo da subtração, pois poderia haver uma tendência da criança a resolver tais problemas através da adição, operação já trabalhada. Vale lembrar ainda que este fechamento, esta especificação da operação a ser utilizada na resolução dos problemas pode se constituir em um entrave para a compreensão das relações entre adição e subtração.

Por fim, foi encontrada uma percentagem de problemas (16\% para adição e 22\% para subtração) que solicitavam o registro dos dados, da operação e da resposta. Nesses casos, a criança ficava livre para decidir qual operação iria realizar, porém o espaço reservado para o registro da solução era também previamente definido. Ou seja, após o enunciado do problema, apresenta-se o seguinte padrão de registro: De fato, em apenas 5\% dos problemas de adição e de subtração observamos um pouco mais de liberdade para a criança escolher a forma de resolver o problema. Vejamos o exemplo abaixo (Construindo na pré-escola, v.3, p.167).

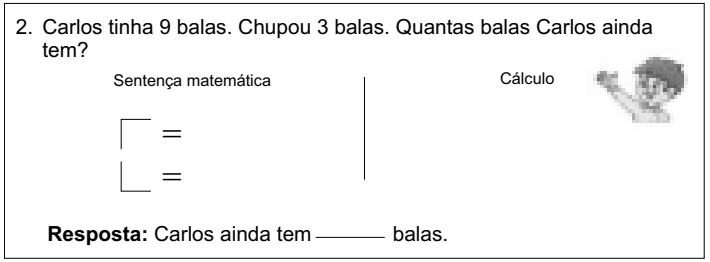

FIGURA 7

Nota-se que, apesar da existência do espaço em branco, há uma expectativa de que o registro da criança obedeça a um certo padrão esperado em termos de sentença matemática, cálculo e resposta. Uma proposta mais interessante seria a possibilidade de um espaço mais livre destinado ao rascunho das crianças, demonstrando que o comportamento de desenvolver estratégias é algo legítimo e desejável no processo de aprendizagem da matemática.

\section{Conclusões}

A partir dos dados apresentados pode-se afirmar que, de um modo geral, os livros didáticos de matemática contemplam a resolução de problemas (principalmente aqueles dirigidos a crianças na alfabetização), considerando, portanto, que tal conteúdo é algo relevante e que pode ser trabalhado com crianças pré-escolares. No entanto, a forma como este trabalho vem sendo proposto pelos autores dos livros parece necessitar de uma reflexão mais aprofundada.

Foi constatada, nos livros didáticos analisados, a ênfase em determinadas estruturas de problemas (combinação e transformação para adição e transformação para subtração), ocorrendo nestes tipos de problema pouca variação no lugar da incógnita, que quase sempre correspondia ao resultado final. Diante de tal proposta, é possível supor que as crianças venham a desenvolver uma compreensão restrita das operações de adição e subtração, pois o que a princípio poderia se constituir em um problema, exigindo reflexão da criança, passa a ser realizado mecanicamente devido à excessiva repetição de um único modelo. 0 mesmo pode ser dito quando observamos certas páginas nos livros didáticos que trazem uma infinidade de problemas exatamente iguais, às vezes até sem variação do resultado final. Em tais casos, mesmo que a criança tenha refletido no início da atividade, rapidamente ela percebe a organização dos problemas propostos, podendo, até mesmo, preencher primeiro todos os resultados para só em seguida colocar os dados dos problemas. Assim, o que deveria ser um problema se transforma em um simples exercício mecânico.

Outro aspecto consistiu no uso de situações-problema que não apresentavam qualquer sentido para a criança. Um problema encontrado em vários livros solicitava, por exemplo, a soma dos valores dos dois lados de uma peça de dominó. Tal situação, com 
certeza, não tem qualquer significado para a criança, pois no jogo de dominó não se faz esse tipo de adição. Ainda nessa mesma linha, outro problema apresentava uma peça de dominó e a criança deveria primeiro somar os valores dos dois lados e em seguida subtrair o valor de um deles. Observa-se, então, que, na tentativa de criar situações-problema contextualizadas, geram-se propostas completamente absurdas, dificultando até a própria compreensão da criança em relação ao que se pede.

Por outro lado, em um dos livros (Fazendo e compreendendo matemática), foram encontrados diversos problemas que buscavam partir de situações do cotidiano, por exemplo, comprar brinquedos ou doces com moedas ou pesar pacotes de bombons, que geravam propostas interessantes envolvendo as operações de adição e subtração. Tal livro também apresentava problemas em que não havia apenas uma resposta correta, estimulando a comparação e discussão de respostas entre as crianças e o professor.

É interessante notar que encontramos, na maioria dos livros didáticos, uma separação entre adição e subtração, aparecendo primeiro os problemas de adição e depois os de subtração. Além disso, como já foi comentado, em grande parte dos problemas não se permitia que a criança escolhesse qual operação utilizar, como se quisessem garantir o uso de um determinado algoritmo, trabalhado naquele momento. Tal proposta parece refletir uma segmentação do próprio ensino de matemática, pois, ainda que reconheçam ambas operações como fazendo parte do mesmo campo conceitual, das estruturas aditivas, tem-se observado na maioria das escolas a separação tradicional no momento do ensino destes conceitos.

Assim, as crianças, em grande número de problemas, não precisam pensar, a operação já é dada, não há espaço para se confrontar soluções e estratégias. Com isso, perdem-se valiosas oportunidades de estimular o pensamento e reflexão da criança a respeito da lógica das operações, suas propriedades em uma situação significativa para ela. A inversão das operações de adição e subtração é um ótimo exemplo disto. Ao invés de se promover espaço para a discussão e comparação de estratégias por parte das crianças, quando um mesmo problema pode ser resolvido tanto por adição como por subtração, especifica-se 0 uso de apenas uma operação. Em outro momento, então, ensina-se à criança sobre as propriedades, ficando tal conhecimento destituído de sentido.

Outro fato observado referiu-se à falta de espaço nos livros para que a criança registrasse espontaneamente a sua estratégia de resolução dos problemas. Como já foi mencionado, o registro das soluções é, em geral, padronizado e a tarefa da criança passa a ser a de preencher quadradinhos. Também em relação às ilustrações, observaram-se vários casos em que, para solucionar o problema, bastava a criança contar os itens do desenho e escrever sua resposta no lugar determinado.

Concluindo, parece importante frisar que, desde a pré-escola, pode haver um trabalho com situações-problema de estruturas variadas, de modo a possibilitar às crianças a aquisição de conceitos mais flexíveis sobre as operações. Tais situações devem ser significativas e exploradas em suas soluções possíveis, estimulando as crianças a formularem hipóteses, trocarem idéias, comparando diferentes estilos de solução e de registros, construindo, relacionando e aplicando os seus conhecimentos matemáticos. Assim como há inúmeras possibilidades para que a escrita ocorra dentro de um contexto de significados, também há diversas situações do dia-a-dia que podem representar excelentes oportunidades para resolver problemas. Para isto é essencial que o educador reconheça o valor deste trabalho para o desenvolvimento da criança, bem como identifique as diferentes estruturas de problemas, considerando a importância de se explorar as estratégias de resolução de seu 
grupo de crianças: seja através do cálculo mental, usando dedinhos, material manipulável ou escrevendo no papel. Nossa análise evidencia, entretanto, que esta não tem sido a concepção que parece orientar as propostas de resolução de problemas apresentadas na maior parte das coleções de livros didáticos de matemática dirigidos à educação infantil.

\section{Referências bibliográficas}

CARPENTER, T.P.; MOSER, J.M. The development of addition and subtraction problem-solving skills. In: CARPENTER, T.P.; MOSER, J.M.; ROMBERG, T. A. (Eds.) Addition and subtraction: a cognitive perspective. Hillsdale: Erbaum, 1982.

CARRAHER, T. , CARRAHER, D.; SCHLIEMAnN, A. Na vida dez, na escola zero. São Paulo: Cortez, 1988.

BARBOSA, J.J. Alfabetização e leitura. São Paulo: Cortez, 1992.

BRANDÃO, A.C.P.; GUIMARÃES, G.L. Alfabetizando sem cartilha: onde está a diferença? Tópicos Educacionais, Recife, V.15, n.1/2, p.19-39, 1997.

FENNEMA, E.; CARPENTER, T.P. Cognitively guided instruction reading. Trad. Zélia Higino. Madison: Wisconsin Center for Education Research. University of Wisconsin, 1991.

GONÇALVES, M.F.C. "Se a professora me visse voando ia me pôr de castigo" - A representação da escola feita por alunos de pré-escola da periferia. In: OLIVEIRA, Z. M. R. (Org.) Educação Infantil: muitos olhares. São Paulo: Cortez, 1994.

GINSBURG, H. Children's arithmetic. New Jersey: D.Van Nostrand Company, 1977.

GROEN, G.; RESNICK, L. Can children invent addition algorithms? Journal of Educational Psychology, Baltimore, n.69, p. 645-652, 1977.

HUGHES, M. Children and number. Oxford: Basil Blackwell, 1986.

KAUFMAN, A. .M.; RODRIGUEZ, M.E. Escola, leitura e produção de textos. Porto Alegre: Artes Médicas, 1995.

NUNES, N.N. 0 ingresso na Pré-escola: uma leitura psicogenética. In: OLIVEIRA, Z. M. R. (Org.) A criança e o seu desenvolvimento: perspectivas para se discutir a educação infantil. São Paulo: Cortez, 1995.

SELVA, A.C.V.; BRANDÃO, A.C. P. Reflexões sobre a aprendizagem de matemática na Pré-escola. Revista Psicologia: teoria e pesquisa, Brasília, v.14, n.1, p.67-75, 1999.

SILVA, W. A. Cala boca não morreu: a linguagem na Pré-escola. Petrópolis: Vozes, 1987.

RILEY, M.S.; GREENO, J.G.; HELLER, J.I. Development of children's problem-solving ability in arithmetic. In: GINSBURG, H.P. (Ed.) The development of mathematical thinking. New York: Academic Press, 1982.

VERGNAUD, G. A classification of cognitive tasks and operations of thought involved in addition and subtraction problems. In: CARPENTER, T.P.; MOSER, J.M.; ROMBERG, T.A. (Eds.) Addition and subtraction: a cognitive perspective. Hillsdale: Erbaum, 1982.

WAJSKOP, G. Brincar na pré-escola. São Paulo: Cortez, 1995.

\section{ANEXO I}

Lista de livros didáticos de matemática analisados:

PEIXOTO, Marilze Lopes; OLIVEIRA, Maria Lúcia de. Bom tempo matemática: alfabetização. São Paulo: Moderna, 1992. 
SACRAMENTO, Márcia Margarida Sampaio. Exercitando matemática: alfabetização. São Paulo: FTD, 1993.

GONDIM, Maria da Salete Alves. Lápis na mão: matemática pré-escola. São Paulo: FTD, 1995.4.

MARSICO, Maria Tereza; CUNHA, Maria do Carmo T. da; ANTUNES, Maria Elizabete M.; COELHO, Armando. Coleção roda-gigante: matemática. São Paulo: Scipione, 1997.

LATERSA, Gislene. Circo dos números: iniciação à matemática. São Paulo: Ática, 1996.

RAMALHO, Lenira Bastos. Sementinha. São Paulo: Ática, 1993. v.1-3.

ALMEIDA, Elinéia. Construindo na pré-escola: matemática. São Paulo: Quinteto Editorial, 1997. v.1-3.

AGRA, Valdira T.; DOMINGOS, Shewa F.; RAMOS, Lielba M. Alves de B. Meu livro, meu mundo. São Paulo: Editora do Brasil S/A, 1989.

VELLOSO, Clausio; DRAGO, Sergio. Matemática números e formas. Rio de Janeiro: Livraria Ciência e Paz, 1995. v.1-2. GUERRA, Isabel Cristina F. Coleção gato xadrez. São Paulo: Scipione, 1995.

LIMA, Marilene M. Vamos aprender matemática. Salvador: Editora do Brasil S/A, 1988.

LIBERMAN, Manhúcia Perelberg; WEY, Regina L. da M. Fazendo e compreendendo matemática. São Paulo: Solução, 1997.

Recebido em 24 jun. 1999

Aprovado em 29 jun. 2000

Ana Carolina Perrusi Brandão é professora do Centro de Educação da UFPE, mestre em Psicologia (UFPE) e doutoranda na University of Sussex. Áreas de pesquisa: resolução de problemas matemáticos; compreensão de textos e aquisição de regras gramaticais em crianças.

Ana Coelho Vieira Selva é professora do Centro de Educação da UFPE, mestre em Psicologia e doutoranda em Psicologia (UFPE). Desenvolve pesquisas sobre a compreensão dos conceitos matemáticos na educação infantil e séries iniciais do ensino fundamental. 